\title{
THE CHOICE BETWEEN ADOPTION AND FOSTER CARE AS CHILD PROTECTION RESPONSES
}

\author{
STEPHEN GAY
}

Child protection systems in Australia are struggling to cope with the growing number of children requiring out-of-home care because of abuse or neglect occurring within families. Professionals and governments are grappling with the alternative care options that are available in an attempt to improve children's health, education and emotional development. Research demonstrates that children suffer if they are exposed to multiple placements throughout childhood and this leads some to believe that the permanency of adoption would better serve the needs of children from broken families. This article considers the recent proposal by the South Australian State Coroner to expand the role of adoption as a child protection response, noting that New South Wales introduced such a model in 2014. It also examines international approaches in this area as well as the findings of studies into foster care and adoption. By drawing together the knowledge gained from different policy and practice approaches to out-of-home care, this article argues that introducing a blanket approach favouring adoption is not an appropriate option. It concludes that the only model likely to achieve the best outcomes for children is one involving individual responses to every child.

\section{CONTENTS}

I Introduction.

II Responding to Child Protection Concerns ......................................................................... 141

III The Different Outcomes of Adoption and Foster Care ....................................................... 143

IV New South Wales Supreme Court on Adoption and Foster Care ............................................ 145

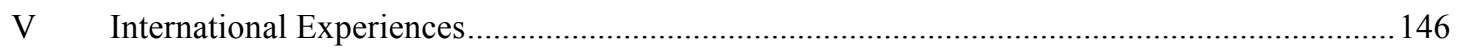

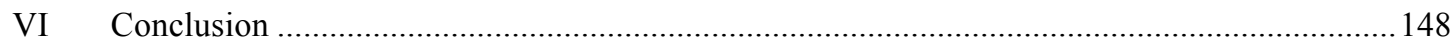

LLB student, School of Law, University of South Australia. 


\section{INTRODUCTION}

With seemingly increasing regularity, the Australian public is exposed to media reports of abuse and neglect of children by their own families. Only the most shocking cases receive media coverage, but this is enough to provide the public with a glimpse of the abuse and neglect of children that occurs in our society. It is confronting and upsetting for many people and often sparks demands for action to ensure that children are not left in abusive environments or placed back in the care of perpetrators. One case that received significant public attention was the 2012 death of four-year-old South Australian girl Chloe Lee Valentine, a child well known to child protection authorities but not removed from her parents prior to her death. ${ }^{1}$ It is not uncommon in circumstances like these for a Coroner to examine how the authorities responded to child abuse concerns about the deceased child. South Australian State Coroner Mark Johns used his findings on the inquest into the death of Chloe to comment on the failure of the relevant government agency, Families SA, to place her in out-of-home care and went so far as to recommend that adoption should have a place in the child protection system. ${ }^{2}$

The Coroner was cautious about suggesting a 'settled model of what the role of adoption in the child protection system should look like,' but given the scarcity of other options, recommended that 'permanent removal to adoptive parents must have a place in the child protection system'. ${ }^{3}$ The Coroner was 'impressed' with Jeremy Sammut's criticism of Australian child protection systems, which strive to keep families together rather than turn to early permanent removal of children through adoption; and noted that '[m]any of Dr Sammut's criticisms were borne out by the evidence in Chloe Valentine's case. ${ }^{4}$ But despite the fact that the existing options of kinship or foster care had not encouraged the authorities to remove the child, the Coroner did not consider whether the additional option of adoption would have made any difference in the case. Nonetheless, the Government of South Australia has given 'in-principle' support to the Coroner's recommendation, subject to the Independent Review of the Adoption Act 1988 (SA) and the Child Protection Systems Royal Commission, both of which are currently underway; and the

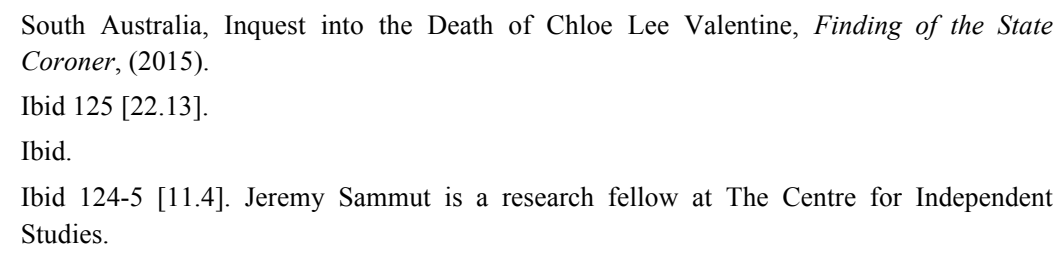


Attorney-General has made it clear that the Royal Commissioner has been asked specifically to consider this recommendation. ${ }^{5}$

Meanwhile, the public continues to be shocked by the small number of cases reported in the media, but few people would appreciate the real scale of the problem. In 2013-14, there were 304097 notifications of child abuse or neglect received by state and territory government agencies in Australia. ${ }^{6}$ As at 30 June 2014, there were 45746 children covered by care and protection orders. $^{7}$

Individual responses are required for every child who comes into contact with relevant agencies because statutory child protection is not a one-sizefits-all system. This presents an almost impossible challenge for a system overwhelmingly reliant on volunteer kinship and foster carers. ${ }^{8}$ The challenge is compounded by the steady decline in the number of foster care families, which often results in placement breakdowns that force children to go through multiple placements while in care - a phenomenon known as 'foster care drift'. Research shows that children can sustain long-term psychological damage if they are constantly separated from carers and moved between placements. $^{9}$

Governments are not unaware of these shortcomings in Australia's child protection systems. Case management is reviewed frequently, commissions of inquiry are established and in the worst cases, inquests into the deaths of children are conducted by coroners. All reviews and investigations inevitably lead to recommendations for changes to child protection systems in the hope that improvement will be achieved and better outcomes for children realised. South Australia is the latest state to undertake a Royal Commission into its child protection system and its report is due in late $2015 .{ }^{10}$ As noted above, the Government of South Australia has asked the Royal Commission to consider the expanded use of adoption in the child protection system.

5 John Rau, 'Child Protection' (Speech delivered at the House of Assembly, Parliament of South Australia), Adelaide, 5 May 2015.

6 Australian Institute of Health and Welfare, Child Protection Australia 2013-14, Child Welfare Series No 61 (2014).

7 Ibid 39.

8 Ibid.

9 Michael Rutter, 'Children in Substitute Care: Some Conceptual Considerations and Research Implications’ (2000) 22 Children and Youth Services Review 685.

10 His Excellency Rear Admiral The Honourable Kevin John Scarce, Governor of the State of South Australia, State Letters Patent, 15 August 2014. 
This article examines the proposed inclusion of adoption as a placement option for children in statutory child protection systems and explores the appropriateness of creating a new adoptive family, which would permanently change a child's legal identity and sever their birth relationships. Part II outlines several responses to child protection concerns and Part III examines the different outcomes of adoption and foster care. Part IV considers the approach taken by the NSW Supreme Court in a case that compared foster care and adoption, and in Part $\mathrm{V}$, the article draws upon international experiences and research in permanency planning to inform options under consideration in Australia. It concludes that, rather than introducing a blanket approach favouring adoption, the only model likely to achieve the best outcomes for children is one involving individual responses to every child.

\section{RESPONDING TO CHILD PROTECTION CONCERNS}

When a child is removed from an abusive or neglectful family environment, decisions about an alternative placement for the child must be made. Subject to the circumstances of each case, child protection authorities will usually look to extended family members or registered foster carers to provide care for the child. ${ }^{11}$ In some cases a form of group home or 'residential' care may be required, but this option is usually considered only after other alternatives have been exhausted or in certain cases of special needs. Agencies develop case plans for children in their care that deal with issues such as family contact, education and health needs. ${ }^{12}$ There might also be a family reunification plan in place as a guiding principle for the child's case management.

For many children, alternative care is temporary, although the duration will vary from case to case. ${ }^{13}$ For others, returning home will never be an option. It is not always clear, at the point when a child enters the statutory child protection system, which category they fall into. It may not be possible to make decisions about permanency planning for a number of years following a child's entry into alternative care. Child protection professionals are then faced with the responsibility for making a decision about how and where to place a child who has come into care. Decisions must be made for children who cannot be reunited with their birth families. Long-term state

11 Judy Cashmore, 'Children in the Out-of-Home Care System' in Alan Hayes and Daryl Higgins (eds), Families, Policy and the Law: Selected Essays on Contemporary Issues for Australia (Australian Institute of Family Studies, 2014) 143.

12 See, eg, Child Protection Act 1999 (Q1d) ss 51(A)-(F).

13 Cashmore, above n 11, 144. 
guardianship may not be an adequate response because it often involves multiple placements throughout childhood, which can lead to a lack of stability for the child and impaired emotional development. ${ }^{14}$ So, the question arises: in order to avoid the 'negative' impacts of foster care, should the child be given an entirely new family, and a new identity, through adoption?

Experts indicate that permanency and stability are essential elements in childhood development. ${ }^{15}$ Foster care does not always provide a child with a stable environment. ${ }^{16}$ This statement does not suggest a lack of dedication on the part of the vast majority of foster carers, but merely reflects the intended 'temporariness' of foster care in many instances. A research brief produced by the National Child Protection Clearinghouse in 2007 reviewed 21 Australian studies that were completed between 2004 and 2006 on outcomes for children and young people in care. ${ }^{17}$ It concluded that '[a]ll of the studies provided evidence that children and young people in care are experiencing relatively negative outcomes when compared to other children not in care'. ${ }^{18}$ Some contributors to this debate see adoption as the antidote to the failings of foster care. ${ }^{19}$ Jeremy Sammut suggested that the Commonwealth Government inter-departmental committee that was established to report on adoption ahead of the May 2014 meeting of the Council of Australian Governments ('COAG') should have recommended that:

$[\mathrm{T}]$ he Abbott government direct the states and territories to take more timely statutory action to permanently remove children from unsafe homes and provide them with safe and stable homes by adoption to suitable families. ${ }^{20}$

However, the communique issued following the meeting of COAG in May 2014 indicated that agreement was reached only on issues relevant to intercountry adoption; it was silent on the issue of adoption as a child protection response. ${ }^{21}$ Notwithstanding the constitutional impediments precluding the Commonwealth from issuing any such direction to states and territories, Sammut did not produce any data about adoption outcomes in his

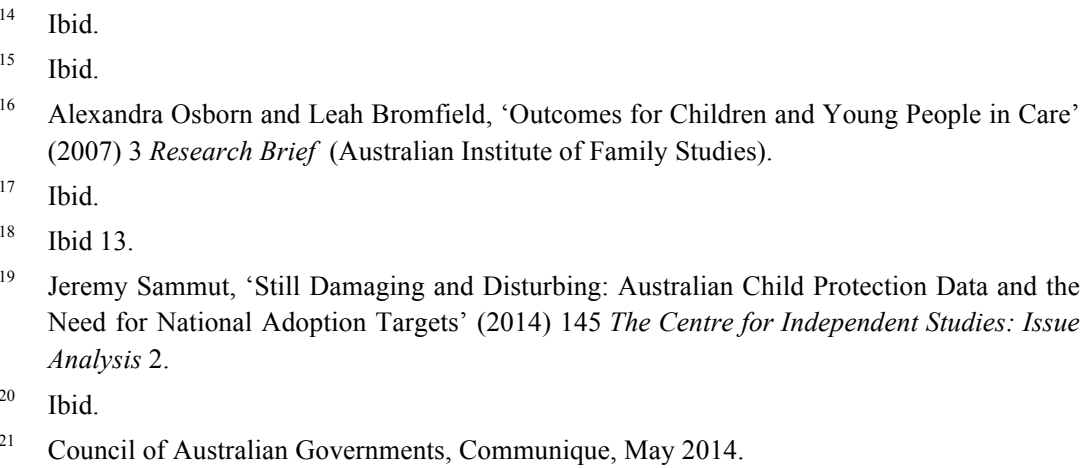


2014 report Still Damaging and Disturbing: Australian Child Protection Data and the Need for National Adoption Targets. ${ }^{22}$ Instead, Sammut focused on well-known flaws in child protection services and presented adoption as a panacea to these failings, apparently for no better reason than the fact that adoption is a long-term care model that is different from foster care.

\section{THE DifFERENT OUtComes OF AdOPTION AND Foster CARE}

Most Australian jurisdictions do not actively pursue adoption as a means to provide a permanent placement following the removal of children from parents after child protection concerns have been raised. The notable exception is NSW. In 2014 NSW implemented amendments to its Children and Young Persons (Care and Protection) Act 1998 (NSW) to 'rank' adoption of children in state care as a higher priority than placement in foster care for some children. ${ }^{23}$ In fact, foster care in NSW is to be considered only after adoption is deemed to be 'not practicable or in the best interests of a child' who is 'unable to be restored to the care of his or her parent. ${ }^{24}$ Adoption from out-of-home care is not currently in vogue in other Australian jurisdictions. However, it is strongly favoured in the United Kingdom (UK) and United States (US). Governments in NSW, the UK and the US have all created systems which purport to focus on permanency planning ahead of family reunification. ${ }^{25}$

While foster care can, in some instances, provide an unstable environment for a child in care, long-term placement can have positive influences on a child's wellbeing. A longitudinal study which examined the wellbeing of young people leaving care in NSW reported that those who had spent at least three quarters of their time in one long term placement while in care were better off than those who had not. ${ }^{26}$ Specifically, Professor Cashmore highlighted that this cohort of children in care:

[A]ttended fewer schools, were happier, were more likely to have completed at least Year 10 at school, to report being able to 'make ends meet', to be satisfied with what the department had done for them, and were less likely to

22 Ibid.

23 Children and Young Persons (Care and Protection) Act 1998 (NSW) s 10A(3)(c).

24 Ibid ss $10 \mathrm{~A}(3)(\mathrm{a}),(\mathrm{d})$.

25 See, eg, Children and Young Persons (Care and Protection) Act 1998 (NSW); Adoption and Safe Families Act 1997 (US); Children and Young Persons Act 2008 (UK); Adoption and Children Act 2002 (UK).

26 Cashmore, above n 11, 146. 
say they missed out on affection and 'things other kids had', or to have thought about or attempted suicide. ${ }^{27}$

This is important because children in out-of-home care generally have worse outcomes in comparison with their peers in areas such as physical health, socio-economic wellbeing and cognitive/learning ability. ${ }^{28}$ There is currently a ground-breaking five-year 'Pathways of Care' longitudinal study occurring in NSW into the wellbeing of children in care. ${ }^{29}$ This study has been underway since March 2011 and aims to provide a new evidence base about the factors that influence wellbeing and outcomes for children in care of all ages and geographic locations. I would argue, however, that the embrace of adoption as a means to secure permanency in out-of-home care is an emotional, rather than evidence-based response to overcoming the known negative outcomes of foster care.

Perhaps adoption does have a place in the child protection system, albeit on an individualised basis. There is little evidence yet in existence that adoption of children from out-of-home care provides better outcomes. However, what evidence there is does not indicate worse outcomes during childhood itself and does suggest greater emotional stability for children. ${ }^{30}$ Early research findings suggest that adoption brings a whole new set of issues for children to grapple with in addition to dealing with past abuse. ${ }^{31}$ Additionally, much is now known about the lifelong effects of adoption and the ongoing support needs of adults who were adopted as children. ${ }^{32}$

Adoption might yet prove to deliver better health and education outcomes for children but at what psychological cost? A study examining children's perspectives on being adopted was conducted in the UK between 2000 and $2004 .{ }^{33}$ The participant base involved a cohort of children adopted between 1996 and $1997 .{ }^{34}$ From the children who were interviewed, 70 per cent had

27 Ibid.

28 Myfanwy McDonald et al, Protecting Australia's Children Research Audit (1995-2010): Final Report' (Australian Institute of Family Studies, 2011) 34.

29 Marina Paxman et al, Pathways of Care: Longitudinal Study on Children and Young People in Out-of-Home Care in New South Wales (Australian Institute of Family Studies, 2014) 15.

30 Elspeth Neil, 'Making Sense of Adoption: Integration and Differentiation from the Perspective of Adopted Children in Middle Childhood' (2012) 34 Children and Youth Services Review 409.

31 Ibid.

32 Senate Community Affairs References Committee, Parliament of Australia, Commonwealth Contribution to Former Forced Adoption Policies and Practices (2012).

33 See Osborn and Bromfield, above n 16

34 Ibid. 
been adopted from out-of-care. The key findings were that almost all children felt 'fully and happily integrated into their adoptive family', ${ }^{35}$ but that 'half of the children had complicated emotions that often included feelings of loss, sadness or rejection in relation to their birth family' ${ }^{36}$ It is suggested that for children requiring out-of-home care, neither fostering nor adoption is a perfect life outcome. Successfully predicting the best fit for each child will continue to be based on individual circumstances, not least the age of the child and the level of abuse or neglect suffered, for some time to come.

\section{New South Wales Supreme Court on Adoption ANd Foster CARE}

In 2006 the New South Wales Supreme Court heard the matter of Application of $A$ : Re D ('Application of $A$ ') which focused on the question of whether adoption or long-term foster care was in the best interests of the child. ${ }^{37}$ The case also considered the relationship between child protection legislation and adoption legislation in that state. ${ }^{38}$ Application of $A$ dealt with two applications: the application of a non-government organisation to have a birth mother's consent to the adoption of her children dispensed with; and the application of the long-term foster carers of two sisters to become their adoptive parents. Justice Palmer approved both applications. ${ }^{39}$

It is important to note that this case analysed NSW child protection legislation prior to the 2013-14 amendments which made adoption a higher priority than foster care. Interestingly, the Court held the Adoption Act 2000 (NSW) to be complementary to the state's child protection legislation, not superior to it. This was explained by Palmer $\mathrm{J}$ in the context of the need for case-by-case consideration:

It would be inappropriate for the Court, by undertaking a review of the literature in the field of child psychology and adoption, to come to the view that, as a general rule, adoption is more likely to be in the best interests of a child than long-term fostering or, indeed, any other form of care... no general rule can be applied. ${ }^{40}$

Justice Palmer continued:

35 Ibid 411.

36 Ibid.

37 [2006] NSWSC 1056.

38 Adoption Act 2000 (NSW); Children and Young Persons (Care and Protection) Act 1988 (NSW).

39 [2006] NSWSC 1056.

40 Ibid [47]. 
In the end, decisions in adoption cases as to what form of care is in a child's best interests are intuitive, founded on the Judge's impression of the particular facts of the case formed in the light of the Judge's experience of life. ${ }^{41}$

These statements made it clear that, despite the decision in this case to dispense with parental consent and grant adoption orders in favour of the foster parents, such an outcome could not be construed as indicating a general preference by the Court for adoption over foster care.

\section{INTERNATIONAL EXPERIENCES}

The child protection systems operating across the US are far more proactive in both terminating parental rights and securing adoptive placements for children in care than Australian child protection systems. Sammut describes the 210 local adoptions in Australia in 2012-13 as 'pitifully low' compared to the more than 50000 children adopted from care each year in the US. ${ }^{42}$ Sammut suggests that if Australia was to arrange adoptions out-of-care at the same rate as the US there would be approximately 5000 adoptions finalised each year. ${ }^{43}$ Furthermore, he explains that in the US, the former Clinton administration's Adoption and Safe Families Act 1997 ('ASFA') provides financial incentives to states to increase the number of adoptions of children in statutory child protection systems. ${ }^{44}$ This is part of Sammut's call for national adoption targets and for the Commonwealth to lead in the area of out-of-care adoption. This represents a marked distinction between the Australian and US approaches to child protection insofar as Australia seeks to offer individualised responses, albeit with far from perfect outcomes, whereas the US sets targets for adoptions of children in care with less emphasis on the unique needs of each child.

One negative outcome of the US approach has been the creation of 'legal orphans'. ${ }^{45}$ As described by the former Chair of the NSW Community Welfare Legislation Review, Professor Patrick Parkinson:

One of the most concerning aspects of the ASFA in the United States is the number of children for whom parental rights have been terminated without an

$41 \quad$ Ibid [51].

42 See Sammut, above n 19, 16.

43 Ibid.

$44 \quad$ Ibid 17.

45 Martin Guggenheim, 'The Effects of Recent Trends to Accelerate the Termination of Parental Rights in Foster Care: An Empirical Analysis in Two States' (1995) 29 Family Law Quarterly 121, 122. 
alternative family being found to provide long-term care. Many children in the United States are kept in limbo without a placement being found. Some 'age out' without an alternative family being found for them. Without action being taken to terminate the parental rights they would at least have some sense of belonging. ${ }^{46}$

Professor Judy Cashmore of the University of Sydney has also remarked upon the phenomenon in the US of 'rushing' to terminate parental rights before an adoptive family has been secured:

Being 'freed' for adoption but 'not chosen' is perhaps one of the worst possible outcomes for children; it leaves them in limbo without a legal parent and is most likely to undermine rather than increase any sense of permanence or security for these children. ${ }^{47}$

The UK has created a system that promotes the use of adoption to achieve permanency planning for children in out-of-home care but has also created a 'middle of the road' position of 'special guardianship'. ${ }^{48}$ This special guardianship model provides foster carers with a level of parental responsibility somewhere short of full adoption. The effect is that:

A special guardian has parental responsibility to the exclusion of any other person (apart from another special guardian). An order will also be able to be made allowing for the child's surname to be changed. A weakness of the model is that there are only modest hurdles to the revocation of a special guardianship. ${ }^{49}$

Child protection and adoption practice in France differs significantly from Anglo-Saxon countries. Annick-Camille Dumaret and Dominique-Jeanne Rosset of the Centre de Recherche Medecine in Paris have stated that '[i]n the French tradition, there is a great reluctance to break family ties' ${ }^{50}$ France has a history of almost 350 years of state support for families facing difficulties following Saint Vincent de Paul's establishment of the Foundling Hospital in Paris in $1670 .{ }^{51}$ Major legislative reform occurred in France in 1983-84 which enshrined the maintenance of the child with his or her family

46 Patrick Parkinson, 'Child Protection, Permanency Planning and Children's Right to Family Life' (2003) 17 International Journal of Law, Policy and the Family 147, 159.

47 Judy Cashmore, 'What Can we Learn from the US Experience on Permanency Planning?' (2001) 15 Australian Journal of Family Law 215, 219-20.

48 See Parkinson, above n 46, 161.

49 Ibid.

50 Annick-Camille Dumaret and Dominque-Jeane Rosset, 'Adoption and Child Welfare Protection in France' (2005) 175 Early Childhood Development and Care 662.

51 Ibid. 
as the first priority closely followed by the retention of parental responsibility even when children have entered out-of-home care. ${ }^{52}$

France's legal system also provides for two models of adoption, namely full or simple adoption. ${ }^{53}$ Such a model enables the creation of 'additional parentage' through so-called simple adoption. ${ }^{54}$ While full adoption closely resembles the model understood in Australia, the UK and US, simple adoption transfers parenting rights to the adoptive family without terminating the legal identity of the child or severing their birth relationships. However, simple adoption in France presents its own difficulties, particularly when conflict between adoptive and birth families arises. ${ }^{55}$ Approximately one third of children classified as wards of the state in France are legally 'adoptable' and finalised adoption rates suggest that most, if not all, of these children are eventually adopted. ${ }^{56}$

The experiences in the US, UK and France show Australia that there are alternatives to viewing child protection as a stark choice between family preservation and permanency planning through adoption. It is possible to design new concepts of parental responsibility instead of persisting with a choice between two 'poles on an ideological spectrum'. ${ }^{57}$

\section{CONCLUSION}

Ultimately, there is no correct answer to the question: is adoption better than foster care? The many variables in the circumstances that bring a child into care are equally poignant when the question of adoption as a long-term care option is considered. In fact, the specific circumstances of each child's life should come into even sharper focus when permanent decisions are being made not only about a young person's childhood, but also about their legal identity for an entire lifetime. It is therefore suggested that an automatic attempt to arrange adoption from care, as occurs in the US and to a lesser extent in the UK and NSW, is inappropriate as a default position.

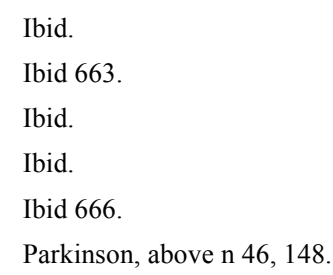


It is known that adoption has lifelong consequences. ${ }^{58}$ In some cases adoption provides a person with a wonderful life filled with love, emotional attachments and stability. In other cases it leaves a void; or a combination of both. In the words of Palmer J:

Research, and the literature in child psychology, confirm ordinary human experience: in order to attain normal, healthy, emotional, intellectual and physical development, children need to feel stable and secure in a nurturing environment, and they need to feel a sense of identity and belonging within their family and in their community. Human experience also tells us that we very often identify ourselves, both to ourselves and in our community, by reference to who and what the State says we are. We are treated as citizens if we have a passport; we are regarded as capable of driving a car if we have a driving licence; we are identified as the children of those whose names appear as our parents on our birth certificates. ${ }^{59}$

Ultimately adoption laws do two things. The first involves securing parental responsibility towards a child, albeit artificially created by legal mechanism. The second relates to the creation of a new identity in law which is retained beyond childhood. This is a profound step to take in order to provide stability.

Adoption was not created to respond to child protection and is perhaps aptly described as 'an awkward fit' within the range of options available for children needing long-term care options. Professor Parkinson reminds us that:

As lawyers, we need to imagine new ways of doing, new ways of seeing, to address the situation of this vulnerable group of children. Then we also need to work hard to ensure that these different concepts of understanding legal parenthood and ensuring stability for children become accepted in the popular imagination as valid ways of constructing familial life with non-biological children. ${ }^{60}$

Today's children in need of out-of-home care are essentially 'trialling' the various models of care that are available to the state in response to their needs. Some models are more intrusive than others. No one model will probably ever completely fit all circumstances. It is most likely that we are yet to construct a flexible, fluid model that best provides stability for children and encompasses a broader definition of parental responsibility. Perhaps France's simple adoption model, or the UK's model of special guardianship,

\footnotetext{
See Cashmore, above n 11, 148.

59 Application of $A$ [2006] NSWSC 1056, [50].

60 Parkinson, above n 46, 168.
} 
ought to be considered as workable models which could be adapted to the Australian context. 